\title{
Uma abordagem deleuzo-guattariana sobre a escola e o vitalismo de seus problemas ${ }^{1}$
}

\section{A deleuzo-guattarian approach on the school and the vitalism of its problems}

\author{
Cintya Regina Ribeiro*
}

\begin{abstract}
RESUMO
O propósito desse estudo é perspectivar uma abordagem filosófica de inspiração vitalista para discutir a escola e os seus problemas, tomando com alvo exatamente os modos como se configuram as condições daquilo que qualificamos como problema ou como sendo da ordem do problemático. Para tal, o trabalho orienta-se a partir de uma filosofia da imanência centrada no pensamento de Gilles Deleuze e Félix Guattari bem como em algumas inspirações em Friedrich Nietzsche articuladas a partir de Deleuze. O percurso investigativo mobiliza três eixos de discussão: a) situar uma abordagem crítica sobre as condições de instauração de um problema, do ponto de vista do plano do pensamento, tomado numa perspectiva de imanência; b) destacar, no interior dessa prerrogativa de imanência, a necessidade de afirmar a coexistência entre as forças de determinação e de indeterminação quando se aborda a escola como um plano de existência, evocando a discussão deleuzo-guattariana sobre agenciamento; c) argumentar em favor de um vitalismo filosófico no campo educacional, apresentando algumas linhas de forças desse modo afirmativo de pensamento, as quais suscitam pensar outro modo de crítica e ao mesmo tempo exigem afirmar uma disposição estética e ético-política frente às condições de emergência daquilo que produzimos como sendo da ordem do problemático.

Palavras-chave: Agenciamento. Escola. Gilles Deleuze. Problema. Vitalismo.
\end{abstract}

1 Esse artigo constitui uma versão modificada e ampliada de uma conferência apresentada junto ao III Congresso da Sociedade Brasileira de Filosofia da Educação/SOFIE, realizado no período de 19 a 21/09/2018, junto a Pontifícia Universidade Católica de Campinas. A pesquisa, base deste trabalho, vem sendo realizada com apoio da Fundação de Amparo à Pesquisa do Estado de São Paulo (FAPESP), processo $\mathrm{n}^{\mathrm{o}}: 2018 / 14902-0$, a quem manifestamos nosso reconhecimento e agradecimento.

*Universidade de São Paulo. Faculdade de Educação. São Paulo, São Paulo, Brasil. E-mail: cintyaribeiro@usp.br - https://orcid.org/0000-0002-7924-4539 


\begin{abstract}
The purpose of this study is to look at a philosophical approach of vitalist inspiration to discuss the school and its problems, targeting exactly the ways in which the conditions of what we qualify as problem or as being of the order of the problematic. To this end, the work is oriented by a philosophy of the immanence centered on the thought of Gilles Deleuze and Felix Guattari as well as on some inspirations in Friedrich Nietzsche articulated from Deleuze. The investigative path mobilizes three axes of discussion: a) to place a critical approach on the conditions for the establishment of a problem, from the point of view of the level of thought, taken from a perspective of immanence; b) to emphasize, within this prerogative of immanence, the need to affirm the coexistence between the forces of determination and indeterminacy when approaching the school as a plan of existence, evoking the deleuzo-guattariana discussion about arrangement; c) to argue in favor of a philosophical vitalism in the educational field, presenting some lines of forces in this affirmative way of thinking, which provoke another mode of criticism and at the same time demand to affirm an aesthetic and ethicalpolitical disposition in the face of the conditions of emergence of what we produce as being of the order of the problematic.
\end{abstract}

Keywords: Arrangement. School. Gilles Deleuze. Problem. Vitalism.

Perspectivar uma discussão sobre a escola e seus problemas, a partir de uma filosofia da imanência, exige um modo de pensamento refratário aos abstracionismos educacionais. Assim, seria inócuo, no interior dessa filosofia, abordarmos os problemas da escola como se escolas e problemas fossem entidades que vivessem por si mesmas, em condição de abstração, circulando como categorias estruturais autônomas, obedecendo aos anseios culturais de um modo de pensamento voltado à generalização e à totalização.

Em nosso entendimento, esse modo de endereçamento fundado em abstrações pode conduzir a algumas formulações universalizantes que, atuando de maneira intensiva e extensiva, tenderiam a fabricar certas evidências consensuais convertidas em verdades educacionais. Destaquemos duas, a título de contextualização: a primeira se basearia na presunção de que uma mirada estritamente teórica poderia dar conta de postular ontologias, sejam de escolas ou de problemas e, a partir daí, produzir conjecturas de reflexão e de crítica, ancoradas num dever ser filosófico, seja ele qual for; a segunda se sustentaria na premissa de que, a partir de dados de mensuração cientificamente coletados e normalizados, seria possível estabelecer uma categoria de real, agora lastreado por uma substância empírica, capaz de expressar um mundo concreto referente 
a escolas e a problemas. Nessa segunda chave aposta-se que, mediante tal procedimento, se viabilizaria lançar, sobre esse real abstraído, uma mirada filosófica também comprometida com algum dever ser.

Ambas as verdades, orientadas por um dever ser sempre legítimo de véspera, guardam em suas tramas linguísticas uma espécie de funcionalismo de ordem filosófica, na medida em que operam a partir de um regime normativo que, definindo um ideal de escola e uma dinâmica sistêmica, estabelecem também a ordem do normal e do anormal, da retidão e do desvio. É essa lógica que culminará na formulação daquilo que, no interior de uma comunidade de pesquisa, será definido e compreendido como problema ou nomeado como sendo da ordem do problemático.

No limite, tais modos de abordar incitam à produção de um efeitoarmadilha: instauram uma plataforma de transcendência, calcada num fundo ideal de valor normativo e, portanto, fazem funcionar, ainda que à revelia, uma ordem de normalização, impulsionando lógicas de governo pautadas em controles biopolíticos, nos termos dos estudos de Michel Foucault (1999, 2008).

No horizonte de uma filosofia da imanência, quando enunciamos "a escola e seus problemas", imediatamente as perguntas se precipitam: Que escola? Qual escola? E, nessa esteira, vêm outras: Quais problemas? Quais os critérios que me facultam qualificar uma dada condição como um problema?

Afirmar uma perspectiva filosófica de imanência obriga colocar sob fogo cruzado não só a orquestração consensual acerca da escola de que falamos, mas a própria condição daquilo que qualificamos e pactuamos como problemático. $\mathrm{Ou}$ seja, exige que nos coloquemos, também a nós, pesquisadores em educação, em situação de espreita investigativa, na medida em que aquilo que está sub judice são nossos próprios modos de pensar e suas implicações nos modos de pesquisar.

Na companhia de Gilles Deleuze $(2000,2001,2006)$, diríamos que se trata de interpelar nossas próprias imagens de pensamento em pesquisa educacional. Mais precisamente, questionar a própria imagem conceitual que construímos de problema. Colocar em causa o estatuto de um problema implica interrogar sobre as condições mesmas que constituem algo como sendo da ordem do problemático. Trata-se, em outras palavras, de desnaturalizar essa pretensa conjuntura problemática como um dado a priori, que nos requisitaria tão somente um gesto intelectivo presumido e culturalmente acordado: dar as respostas assertivas àquilo que os problemas manifestam sob a forma de perguntas.

Transtornar esse roteiro linear que atrela um problema a uma maquinaria já cifrada de perguntas e respostas, para, em seguida, capturar a vida da escola nessa mesma trilha, parece-nos um procedimento de primeira grandeza para demarcarmos a nervura de nossa discussão. 
Propomos, assim, um percurso em três momentos, apropriando-nos de plataformas de discussão trazidas por Gilles Deleuze $(2000,2001,2006)$ bem como pela parceria filosófica entre este pensador e Félix Guattari (1992, 1995a, 1995b, 1997, 2014). No primeiro deles, buscamos situar uma abordagem crítica sobre as condições de instauração de um problema, do ponto de vista do plano do pensamento, tomado numa perspectiva de imanência; no segundo, destacamos, no interior dessa prerrogativa de imanência, a necessidade de afirmar a coexistência entre as forças de determinação e de indeterminação quando se aborda um plano de existência - como, por exemplo, o de uma escola e seus problemas - evocando a discussão deleuzo-guattariana sobre agenciamento; por fim, buscamos, a partir das incursões pregressas, argumentar em favor de uma abordagem filosófica de inspiração vitalista no campo educacional, apresentando algumas linhas de forças desse modo de pensamento.

\section{A construção do problema como nosso alvo de problematização}

Deleuze (2006) lança mão de um enunciado de Marx no qual este afirma que "a humanidade só se coloca as tarefas que ela é capaz de resolver". E engata a seguinte provocação:

A solução é sempre aquela que uma sociedade merece, que ela engendra em função da maneira pela qual soube colocar, em suas correlações reais, os problemas que se colocam nela e para ela nas relações diferenciais que encarna (DELEUZE, 2006, p. 265).

Se a virulência dessa afirmação primeiro nos paralisa, em virtude de sua clareza histórico-filosófica, em seguida, inevitavelmente também nos impele à urgência de outras atmosferas de pensamento. Ora, é com assombro que deparamos com a endogenia de nossos processos de naturalização do pensar: se insistirmos em colocar os problemas sob a égide de um mero ato reflexivo de perguntas e respostas, teremos exatamente o efeito que merecemos. Então, como prosseguir na existência, para além dessas tautologias, diante da obviedade desconcertante desse efeito-rebote? 
Para o pensador francês, uma pergunta, uma questão, uma interrogação não se confundem como forma de expressão de um problema assim como uma resposta não se traduz como sua solução.

Em Diferença e Repetição, Deleuze (2006, p. 225-226) nos alerta:

[...] a interrogação [...] é sempre feita num quadro de uma comunidade: interrogar implica não só um senso comum, mas um bom senso, uma distribuição do saber e do dado em relação às consciências empíricas, de acordo com suas situações, seus pontos de vista, suas funções e competências, de tal maneira que uma consciência é tida como já sabendo o que a outra ignora (que horas são? - você que tem ou está perto de um relógio. Quando nasceu César? - você que conhece história romana).

Um problema disposto em termos de um jogo de perguntas e respostas se funda num princípio de transcendência, que demanda um lugar referencial de exterioridade para sua validação: tanto o modo de colocar o problema já advém de uma imagem dogmática referente àquilo que é considerado como problema, quanto o jogo de perguntas e respostas já traz subsumido o repositório transcendental de um saber - um oásis de conhecimento - a partir do qual serão pinçadas tanto as questões quanto as respectivas soluções. Diante desse quadro, em Lógica do sentido, Deleuze (2000, p. 57) faz a seguinte convocação:

Devemos, assim, romper com um longo hábito de pensamento que nos faz considerar o problemático como uma categoria subjetiva de nosso conhecimento, um momento empírico que marcaria somente a imperfeição de nossa conduta, a triste necessidade em que nos encontramos de não saber de antemão e que desapareceria com o saber adquirido.

O chamado exige desfazer o amálgama que, por acionar uma operação de cunho transcendental, ata um suposto sujeito do conhecimento a um também suposto conhecimento como locus da verdade. É essa imbricação que faz de um problema mera expressão de uma verdade em situação de errância.

Numa chave de imanência, a aposta é outra: trata-se de pensar o problema ou o problemático não como um dado, uma imagem de pensamento a priori, mas como um efeito, uma emergência singular, imanente às próprias circunstâncias do ato de pensar. Como afirma Deleuze (2000, p. 57), "um problema, com efeito, não é determinado senão pelos pontos singulares que exprimem suas condições". 
Isso reposiciona também aquilo que chamamos de solução. Para Deleuze (2006, p. 57) a solução "deve provir da forma do problema". Nas palavras do próprio filósofo: a resolubilidade "deve ser determinada pelas condições do problema, ao mesmo tempo que as soluções reais devem ser engendradas pelo e no problema" (DELEUZE, 2006, p. 233, grifos do autor).

Atentemos aos grifos de Deleuze: soluções engendradas pelo e no problema. Há uma dinâmica performativa aí, portanto, que faz patinar uma prerrogativa de transcendência, exigindo uma investida outra, que possa fazer falar as situações de imanência como forças constitutivas do próprio campo problemático.

A radicalidade dessas ideias transversaliza e implica nosso campo de pesquisa educacional de modo irreversível, ensaiando outras potências. Particularmente, no escopo do presente estudo, essa disposição performativa assim se manifesta: instauram-se, in loco, as circunstâncias de uma espécie de jogo-escola. Nessa instauração, a escola, em vez de ser tomada como um ser, configura-se como um modo de ser, um modo de existir. E é esse modo de existência escolar que - em sua performance como modo e não como um ser - produz suas texturas e tessituras, em razão mesmo das contingências dessa maneira singular de existir. Assim, são essas rugosidades e lisuras que, dizendo de um movimento contínuo e infinito, fazem falar as forças vivas que ali se compõem e se agitam, intempestivamente.

Estudos que focalizam a escola, a partir de uma perspectiva deleuzoguattariana, têm reverberado, cada um a seu modo, essa tensão entre, de um lado, uma imagem de escola cunhada pelo imperativo da forma, ou seja, de sua forma institucional clássica; de outro, uma mirada que privilegia elementos particulares, locais, contingentes, explorando dessa escola os fluxos informes e moventes que a constituem. $\mathrm{O}$ enunciado seguinte denota esse esforço de situar o objetivo de uma pesquisa educacional conduzida nessa frente:

Todo dispositivo - incluindo a fortiori o dispositivo escolar - não é homogêneo, sendo sempre, de algum modo, desequilibrado pelo heterogêneo, atravessado pela ambigüidade do equívoco; logo, sujeito a rupturas e a transformações para além das capturas, e aberto a agenciamentos de criação/invenção. Compõem esta narrativa - que tem como expectativa primeira apontar a possibilidade de brechas na homogeneidade lógica do dispositivo escolar, pequenos rompimentos fazendo brotar frágeis linhas de subjetivação/criação (AXT, 2004, p. 222). 
A preocupação em afirmar uma análise circunscrita da escola também é um acento dessa vertente, tal como lemos na introdução desse outro estudo:

\begin{abstract}
Desse modo, busca-se pensar o território escolar a partir da luta de forças que constituem as instituições: forças de produção e reprodução; moleculares, micropolíticas e molares, macropolíticas. [...] Interessam-nos os movimentos de constituição do território a partir da análise das singularidades de uma escola específica, investigando os efeitos de suas composições, isto é, suas paisagens geradas a partir de agenciamentos territoriais e individuações sucessivas (OLIVEIRA; FONSECA, 2006, p. 136).
\end{abstract}

Essa atenção diferencial à vida da escola exige uma modificação nos modos de pensamento em pesquisa. Sandra Corazza aborda esse aspecto a partir da discussão da linguagem, ou mais especificamente, da "gagueira da linguagem" (DELEUZE; PARNET, 1998, p. 71; DELEUZE, 1997) por meio da qual a pesquisadora lança a questão provocativa: "O que faz gaguejar a linguagem da escola?", convocando-nos ao deslocamento do pensamento e, portanto, dos modos tanto de formulação de problemas quanto de seus endereçamentos.

Por isso o que importa à linguagem pós-crítica é o "escalonamento" de novas linguagens. Fazer "viradas" da Escola, da Pedagogia, e de nós próprias/os é mudar o escalonamento vigente, deslocar as palavras e o pensamento educacionais. A constituição dos "objetos" de pesquisa e ensino não dizem tanto respeito às "temáticas" ou aos "conteúdos", mas a uma linguagem. Os objetos deixam-se "apreender" quando são formulados por uma "teoria-linguagem", não a partir dos "dados" da "realidade", nem de operações "cognitivas” abstratas (CORAZZA, 2000, p. 101).

Ao apostar em modos de pensar capazes de lidar com a emergência das singularidades, uma filosofia da imanência faz da imponderabilidade um elemento estratégico para uma perspectivação mais potente da escola. Nesse espectro podemos destacar o horizonte das pesquisas escolares de orientação cartográfica, nos termos de Deleuze e Guattari (PASSOS; KASTRUP; ESCÓSSIA, 2014; PASSOS; KASTRUP; TEDESCO, 2016; MOLIN, 2011). Mas além disso, é importante ressaltar que a discussão deleuzo-guattariana sobre escola também é conduzida a partir de recortes temáticos advindos dos diferentes campos de pesquisa em educação. A despeito de não se constituir como 
alvo de nosso presente trabalho, citamos alguns estudos nessa direção, tendo em vista tão somente uma exemplificação da amplitude do escopo: pesquisas sobre ensino e/ou educação de disciplinas (GALLO, 2012; GELAMO, 2009; CLARETO; MIARKA, 2015), sobre formação de professores (DIAS, 2011; RODRIGUES; SCHWANTZ, 2016), sobre currículo e/ou didática (AMORIM, 2018; CORAZZA, 2017; FERRAÇO, 2016; MEYER; PARAÍSO, 2012), sobre gestão escolar (BARROS; FONSECA, 2009), entre inúmeros outros.

É também nessa atmosfera do imponderável da vida escolar que situamos nossa discussão acerca das condições de construção de um elemento problemático. Em nossas vontades de governo, poderíamos nomear incêndios, abismos, dissonâncias - tudo o que se faz excessivo à retidão do pensamento - como problemas. Mas, se insistimos na premência de fazer girar o pensamento, recusando a ideia de problema como desvio em relação ao imperativo da norma, faz-se necessário afirmar a disposição intempestiva das forças em jogo e criar outros modos de enfrentamento de seus efeitos.

No intuito de explorarmos criticamente as nuances desse trabalho do pensamento que forja um problema, defendemos que se torna indispensável desmontar o insistente antagonismo de duas linhas de forças que aí se anunciam e que parece contribuir fortemente para a consolidação dessa imagem do problemático como sendo ruído, falha, escape, etc. Tais linhas referem-se aos movimentos de determinação e de indeterminação. Eis o objetivo de nosso próximo tópico.

\section{Determinação e indeterminação: efeitos em coexistência}

Uma prerrogativa de imanência, na companhia deleuzo-guattariana, e agora também nietzschiana, propõe ultrapassar esse binarismo - que dispõe o existir de uma força em detrimento do existir de outra - , convidando-nos a tomar as forças em uma dinâmica de composição, de agenciamento.

De acordo com Deleuze e Guattari (1995a, 1995b, 1997, 2014), um agenciamento se produz da conjunção de elementos heterogêneos, com suas conexões que ao mesmo tempo delineiam territórios e incitam seus próprios movimentos de desterritorialização. Nesse sentido,

a única unidade do agenciamento é de co-funcionamento: é uma simbiose, uma "simpatia". O que é importante não são nunca as filiações, mas as alianças e as ligas; não são os hereditários, os descendentes, mas os contágios, as epidemias, o vento (DELEUZE; PARNET, 1998, p. 83). 
Nessa perspectiva, determinar e indeterminar seriam tão somente efeitos qualitativos efêmeros, decorrentes das singulares relações entre as forças, ou dos modos como estas se compõem ou se agenciam, em suas alianças e disputas. Assim, recusar uma abordagem polarizada das forças implica afirmar movimentos de composição, com suas disposições produtivas e, poderíamos afirmar, vitais.

Tomar as forças em sua dinâmica de agenciamento possibilita-nos escapar de um modo dualista de pensamento e explorar outras maneiras de lidar com a instabilidade e a mudança. Multiplicidade e variação emergem, assim, como duas importantes frentes. A primeira, por enfatizar a conjunção entre forças díspares. Afinal, "agenciamento algum pode ser qualificado segundo um fluxo exclusivo" (DELEUZE; PARNET, 1998, p. 117). A segunda, por acentuar a disposição radicalmente metamórfica dessas múltiplas conexões em movimento. Assim, para Deleuze e Guattari (1995a, p. 17), "um agenciamento é precisamente este crescimento das dimensões numa multiplicidade que muda necessariamente de natureza à medida que ela aumenta suas conexões".

Cabe destacar, ainda, a prerrogativa de imanência aí em jogo. Deleuze e Guattari (1995b, p. 20) chamam a atenção em relação a esse ponto: "os agenciamentos não cessam de variar, de ser eles mesmos submetidos a transformações. Em primeiro lugar, é necessário fazer intervir as circunstâncias". Ora, são tais circunstâncias que conferem vitalidade às forças, implicando em seu maior ou menor gradiente de potência.

Afirmar a condição circunscrita dos múltiplos fluxos e suas conectividades, bem como a situação de variação que aí opera, constitui-se, a nosso ver, como um recurso estratégico para a ativação de uma perspectiva de imanência em relação às forças.

Seguindo tais formulações, os efeitos de determinação e indeterminação não podem ser abstraídos como valores prévios em si mesmos, numa simplista distribuição entre positivo e negativo, bem e mal etc. Ao contrário: exatamente em razão da vitalidade das forças - com suas alianças e suas refrações singularizando modos de agenciamento, ou seja, distintos modos de existência no mundo - deflagra-se um complexo processo de valoração aí subsumido.

Encontramo-nos na pulsação da imanência. Aqui, precisamos convocar a sagacidade de Friedrich Nietzsche, trazida por Deleuze (2001): as forças de indeterminação e determinação serão abordadas por Nietzsche em termos de acaso e necessidade, respectivamente.

Para o pensador alemão, acaso e necessidade não se opõem, não se excluem mutuamente. Afirmar o acaso, a indeterminação, implica bancar as condições que necessariamente se desenham num certo jogo e que assim se organizam como um campo de determinação, configurando um território contingenciado. 
Essa instauração, por ser indissociável daquele contexto, se impõe, portanto, como efeito de uma configuração necessária. Mas exatamente por remeter a um contexto dado e não a outro qualquer, tal instauração emerge e se afirma como tão somente um lance possível de jogo que, ali, eventualmente ganhou forma. Assim estabelecida, essa situação, a despeito de conformar-se como uma determinação, encontra-se imantada pelas forças intempestivas que lhe abrem ao devir, acionando, assim, novamente o acaso e mantendo vivo o furor de indeterminação que se virtualiza nesse movimento contínuo do jogar.

"Nietzsche faz do acaso uma afirmação", enfatiza Deleuze (2001, p. 42). Com isso, a indeterminação não é valorada como uma força de sinal negativo, $a$ priori, como se devesse ser rechaçada e combatida em favor de uma determinada ordem previamente acordada entre os homens. Convidando-nos a outra dança de pensamento, essa perspectiva faz da indeterminação uma das forças que compõem as movimentações dos jogos. Assim, afirmar o acaso, acolher a indeterminação, implica abraçar as disposições fáticas, ou seja, os contornos de determinação engendrados por esse acaso e que então somente ali singularmente se efetivam, se atualizam.

Mas aqui é preciso trazermos à pauta o elemento diferencial que anima toda essa discussão. É crucial atentarmos em que a empreitada nietzschiana, para ultrapassar o impasse clássico que coloca a determinação e a indeterminação como lugares antagônicos e excludentes, não busca a saída nos dispositivos da racionalidade com suas estratégias de superação das contradições. Pressupor a coexistência das forças de determinação e de indeterminação não se reduz a mero exercício de afirmar uma proposição como condição lógica para erigir um argumento filosófico.

Para escapar do dualismo, afirmando a coexistência de tais forças, fazse imperativo acionar um vetor ético, tendo em vista bancar um modo de posicionamento no interior desse campo movente. Assim, a cada afirmação do acaso, e consequentemente dos contingenciamentos fáticos ali emergentes, exige-se sustentar a virtualidade das forças que ali se agitam, em devir, e que, portanto, reintroduzem uma potência de indeterminação no próprio movimento de determinação.

"Saber afirmar o acaso é saber jogar", diz Deleuze (2001, p. 43). Poderíamos inverter, portanto: para jogar bem é preciso afirmar as condições de indeterminação aí implicadas. Qual é o jogo? Como jogar? Qual o próximo lance? Quando disparar a próxima partida? Tais perguntas não se respondem com a aplicação de um dispositivo técnico-científico ou de uma grade de fundamentos filosóficos. Essas questões vivas nascem no fluir performático do próprio ato de jogar e só ganham sentido ali, enquanto se joga. 
Ora, esse gesto de bancar as determinações do jogo e ao mesmo tempo insistir na indeterminação do próximo lance, na virtualidade da próxima partida, é um gesto ético por excelência. Implica trazer à temporalidade do jogar uma variação que não se curva à ordenação da racionalidade, científica ou filosófica, mas se faz na modulação do mundo dos valores. Cada ato, cada lance afirmado guarda em si os processos genealógicos de valoração que delinearam aquele agenciamento das forças, que instauraram aquele modo de existência, que engendraram aquela forma de vida (NIETZSCHE, 1998).

Por isso, o enfrentamento dessas questões exige levar em consideração uma avaliação, in loco, dos valores que ali vibram, modulando os agenciamentos, conferindo plasticidade aos contornos das determinações. Somente uma atenção problematizadora frente aos valores que investiram e atualizaram as forças em jogo poderia abrir passagem às linhas virtualizadas que ali também vivem, incitando, assim, outros modos de vir a ser. Vemos, portanto, a coexistência de movimentos díspares, pois como enfatizam Deleuze e Guattari (2014, p. 154),

"um agenciamento tem pontas de desterritorialização, ou, que dá no mesmo, que ele tem sempre uma linha de fuga, pela qual ele mesmo foge, [...] ou que dá no mesmo, que o agenciamento se estende ou penetra em um campo de imanência ilimitado".

Essa discussão é importantíssima quando nos voltamos a discutir a escola e seus problemas do ponto de vista de uma filosofia da imanência, que presta atenção a esses movimentos intempestivos, ressaltando as dinâmicas dos modos de existência, dos modos de ser e de vir a ser, em detrimento das demarcações ontológicas que fixariam, de largada, o ser da escola ou o ser de seus problemas. Quando afirmamos uma perspectiva de imanência em relação a tais questões, reposicionamos nosso foco de discussão, tomando a escola, agora, como um modo de ser, ou seja, como uma forma de vida.

\section{Em favor de uma abordagem filosófica vitalista}

Em razão dessa guinada, entendemos que falar de problemas de escola é, sobretudo, falar do vitalismo que aí se encontra implicado. Tomamos vitalismo numa inspiração nietzschiana: "um pensamento afirmativo, um pensamento que 
afirma a vida e a vontade na vida" (DELEUZE, 2001, p. 56). Trata-se, em outras palavras, de um modo de pensamento que afirma a vida como medida irredutível de valor, ou seja, que considera a vida como possuindo valor em si mesma, não podendo ser reduzida a qualquer condição que lhe seja alheia.

É preciso reconhecer que ao situarmos a vida na centralidade do jogo, afirmando-a como elemento crucial, estamos realizando um ato arbitrário de valoração. Portanto, não se trata de uma naturalização da vida como valor dogmático, como um fundamentalismo. Ao trazermos à cena essa discussão, uma questão imediatamente desponta: mas de que se trata isso, a vida?

Sigamos com as pistas de Nietzsche, quando ele aciona a pergunta: "Que significa viver? Viver [responde ele] - é continuamente afastar de si algo que quer morrer; viver é ser cruel e implacável com tudo o que em nós, e não apenas em nós, se torna fraco e velho" (NIETZSCHE, 2001, p. 77).

Vemos como as ideias acerca do que é vital ou mortal não possuem sentidos de antemão. É uma operação de valoração — de cunho histórico, filosófico, sociológico, antropológico, político etc. - que poderá qualificar algo como sendo da ordem da vida ou da morte, da força ou da fraqueza, da potência ou da impotência etc.

Essa ressalva é importante, pois, por mais surpreendente que possa parecer, o enunciado que diz ser a vida um valor irredutível não guarda em si mesmo uma verdade essencial. Em outras palavras, a vida não guarda em si seu próprio salvo-conduto. A vida precisa ser defendida e essa defesa não se dá como um jogo ganho a priori, mas demanda uma disposição combativa, in loco, em meio a tantas outras disputas, movidas por tantos outros valores.

Por isso, afirmar a vida, defender a vida, é um ato político e um gesto ético, pois implica bancar um posicionamento e seus efeitos num jogo de forças, e não meramente levar a bom termo o percurso lógico de uma argumentação.

Estamos diante de uma torção aguda, que nos impulsiona em outra direção, extremamente profícua. $\mathrm{O}$ valor da vida, ou a vida como valor radical, não se justifica por uma fundamentação de ordem transcendental. Na perspectiva de uma filosofia da imanência, uma defesa aguerrida da vida carrega sua deriva inevitável, qual seja, enfrentar as perguntas que movem as lutas nas arenas: que vida? Que modo de vida é considerado vida? Que forma de vida é tomada como legítima?

Há aí um combate entre forças, em dois tempos: primeiro, implica bancar a afirmação da vida como valor central, como objeto da luta; segundo, implica sustentar o embate daí decorrente que tenderá a dispor, nessa arena, distintos modos de vida em disputa pela legitimidade de existir. "Nietzsche diz efetivamente que a força tem uma outra força como objeto. Mas precisamente, é com outras forças que a força entra em relação. É com uma outra espécie de vida que a vida entra em luta" (DELEUZE, 2001, p. 15, grifos do autor). 
Esse modo de enfrentamento constitui a nervura daquilo que aqui qualificamos como uma abordagem filosófica vitalista. Fica evidente que esta abordagem recusa uma perspectiva de transcendência, uma vez que, como apontamos, a centralidade do valor da vida e a defesa pela singularidade das formas de vida não se oferecem como fundamentos de verdades transcendentais. Fica evidente, também, que ao configurar-se no interior de uma filosofia da imanência, tal vitalismo exige levar em conta o calor das disputas in loco, condição que suscita tomadas de posição, demandando, assim, o acionamento do campo dos valores e, portanto, trazendo às ações sua dimensão de natureza política e ética.

É crucial, entretanto, destacarmos a singularidade desse modo como estamos tratando a questão das lutas, das disputas, a partir desses rastros deleuzo-guattarianos e nietzschianos. Afirmar a vida diz respeito a uma condição agonística, porém não reativa. A partir de Nietzsche, Deleuze (2001, p. 275-276, grifos do autor) situa esse pensamento afirmativo:

Afirmar, é ainda avaliar, mas avaliar do ponto de vista de uma vontade que frui a sua própria diferença na vida [...] Afirmar não é carregar-se, assumir aquilo que é, mas libertar, descarregar aquilo que vive. [...] não carregar a vida com o peso dos valores superiores, mas criar valores novos que sejam os da vida, que façam a vida leve e activa. Só existe criação propriamente dita na medida em que, longe de separar a vida do que ela pode, nos servimos do excedente para inventar novas formas de vida.

Aqui, afirmar diz respeito à criação de valores que possam engendrar modos outros de existência. Por isso, não se trata de uma frente reativa, pois não remete ao mero confronto de sustentação de fardos na arena da cultura.

Essa discussão filosófica sobre vida e vitalismo, numa atmosfera de imanência e num horizonte de pensamento afirmativo, nos possibilita fecundar outros modos de investida no campo educacional. O desafio de trabalharmos numa seara filosófica de imanência, em educação, particularmente quando nos voltamos a focalizar a escola, encontra-se exatamente nessa condição arredia, na qual não dispomos de métricas de valores lastreados de véspera que possam nos conduzir assertivamente à ação-mestra em relação aos supostos problemas. Mas é exatamente em razão dessa marca de indeterminação, de vacilação, de escape, e ao mesmo tempo, esse posicionamento radicalmente afirmativo da vida, que faz com que aquilo que chamamos de problemas aqui adquira outro valor de existência, possibilitando outros agenciamentos. 
Um problema assim o é não por dizer de um desvio em relação a um fundamento, mas por dar a ver o vitalismo das forças beligerantes, em ato. Por isso, o problema diz não de si mesmo, como uma entidade referencial, ontológica, mas da própria problemática que alimenta as lutas em jogo, com todas as nuances dos litígios e acordos que as movem. Os problemas dizem de histórias aguerridas. Clamam menos por uma solução e mais pela agudeza de um pensamento que possa dar conta de extrair de suas forças as linhas vibráteis de um corpo vivo.

Pinçar a sutileza disso parece-nos de uma relevância ímpar para conseguirmos, como pesquisadores educacionais, suspeitar de uma abordagem transcendental acerca de problema em favor de uma perspectiva de imanência em relação, agora, à própria vida de uma problematização.

Se tomamos a escola não em sua condição de ser, mas de seus modos de agenciamento, de seus modos de existência, podemos afirmar que sua vida é feita do gradiente intempestivo de suas forças, engendrando, portanto, nesse movimento mesmo, os modos de existir de seus próprios problemas. Aqui, longe de quaisquer vicissitudes reativas, afirmar o vitalismo de uma escola é afirmar o vitalismo de seus problemas, portanto.

\section{Considerações finais}

Afirmar uma abordagem vitalista em educação implica bancar a zona de indeterminação que se instaura quando os enunciados assertivos não respondem mais às demandas das lutas, sobretudo contemporâneas, as quais exigem lidar com um mundo no qual valores díspares disputam suas possibilidades de coexistência.

Numa escola, onde pulsam inúmeras e distintas vidas, se disputa exatamente o direito à vida, à afirmação de modos de vida singulares, ou ainda, à criação de valores que possam engendrar modos outros de existir.

Assim, a nosso ver, é preciso focalizar a radicalidade da questão que aqui se manifesta: as discussões que remetem à escola e seus problemas se endereçam à vida como valor central. Haveria, assim, uma vida intensa do pensamento quando uma escola se agita em suas problematizações.

Afirmar o vitalismo de escolas e de seus problemas afiança um modo de pensamento afirmativo em relação à própria condição exuberante da vida. Tal horizonte nos aponta algumas linhas de força no encontro com nossas questões educacionais. 
A primeira delas sinaliza a criação de outras práticas de crítica: trata-se de escapar do dualismo que repousa numa atitude crítica fundada na oscilação pendular entre um ato diagnóstico e um ato prescritivo em relação ao campo educacional. Na medida em que os problemas podem ser tomados como signos em movimento que dão a ver a vida intempestiva das forças constitutivas da escola, o pensamento se lança a outras paragens, abdicando de uma tarefa linear de fazer cumprir um dever ser de escola, lastreado por uma mirada normativa em relação ao mundo dos problemas. Esse deslocamento pode suscitar um outro modo de crítica, agora afeito à criação, na medida em que, ao agenciar as forças escolares de problematização de maneiras distintas, abre passagens da experiência escolar para outras conexões. Já não se trataria de julgar a composição das forças, mas de maquiná-las de modos diferentes, arranjando-as criativamente, tendo em vista ensaiar outros possíveis.

A segunda linha de destaque conclama a uma incursão de natureza estética: numa discussão sobre pintura em $\mathbf{O}$ que é a filosofia?, um enunciado nos captura: "O vazio colorido, ou antes colorante, já é força" (DELEUZE; GUATTARI, 1992, p. 234). Eis o convite a um pensar sensível, capaz de romper com o imperativo do sentido de tal modo que, retirando a indeterminação desse lugar estéril do não-sentido, já a faz funcionar como um vetor de força. Essa situação denota a necessidade de um modo de pensar que, em sua condição diferencial, possa dar continência à sensível demanda que aqui se impõe: como flagrar a corporalidade vibrátil de uma escola? Se ali tudo é feito de forças em relação, faz-se necessário, num ato incansável de artista, um trabalho de criação, de estilização de um modo de pensamento outro que possa ultrapassar a linearidade do campo do sentido, no qual se polarizam verdades a partir da polarização de valores.

A terceira linha de força convoca a uma discussão de ordem ético-política: nos encontros das forças, no campo escolar, instauram-se zonas de indeterminação refratárias aos nossos esforços de identificação, classificação e controle. Os problemas despontam como uma ocasião estratégica na qual se dá o flagrante de uma economia política das forças ali agenciadas. Assim, bancar a presença da indeterminação implica renunciar a um modo dualista de pensamento a fim de levar adiante a pista ético-política da pergunta deleuzo-guattariana que se impõe de maneira inarredável: "qual é a aptidão de um agenciamento para transbordar seus próprios segmentos, ou seja, para se abismar na linha de fuga e para se espalhar no campo da imanência?” (DELEUZE; GUATTARI, 2014, p. 156-157). No esteio dessa interrogação, uma vez esgotado o circuito de perguntas e respostas ofertado pela cultura, uma outra interpelação se impõe, aguda, a nós, pesquisadores educacionais: quanto o campo da educação suporta o vitalismo da 
indeterminação com seus efeitos imponderáveis? Por exigir um gesto valorativo que supõe afirmar, de largada, o risco da indeterminação, trata-se, em nossa perspectiva, de uma das mais importantes questões de cunho ético e político com a qual nos defrontamos na contemporaneidade, tanto no campo educacional quanto nos mais diversos âmbitos da vida social.

Tais apontamentos nos convidam a pensar que afirmar o vitalismo da indeterminação supõe manter sempre aberto um campo problemático como uma espécie de zona de respiração, em fluidez e espreita. A nosso ver, a sustentação desse campo problemático permitiria colocar um problema em fluxo contínuo de variação, assegurando sua atualidade e afirmando sua virtualidade. É a atenção ao agenciamento singular das forças de problematização que fazem da escola, uma escola. Por essa razão, nessa abordagem filosófica vitalista, se os problemas são nossa tempestade, são também nossa bússola.

\section{REFERÊNCIAS}

AMORIM, Antonio Carlos R. Deslocamentos entre currículo e estudos de cinema experimental. Práxis Educativa, Ponta Grossa, v. 13, n. 3, p. 1025-1043, set./dez. 2018. Disponível em: file:///C:/Users/Usu\%C3\%A1rio\%20UFPR/Downloads/12238-Texto\%20 do\%20artigo-209209212995-1-10-20180824.pdf. Acesso em: 01 nov. 2018.

AXT, Margarete. Civitas, a cidade viva: ou de um espaço para o acontecimento-invenção na escola. Educação \& Realidade, Porto Alegre, v. 29, n. 2, jul./dez. 2004. p. 219-235. Disponível em: https://seer.ufrgs.br/educacaoerealidade/article/view/25404/14735. Acesso em: 01 out. 2018.

BARROS, Maria E. B.; FONSECA, Tania M. G. Gestão escolar. In: AQUINO, Julio G.; CORAZZA, Sandra Mara (orgs.). Abecedário: educação da diferença. Campinas: Papirus, 2009. p. 78-82.

CLARETO, Sonia; MIARKA, Roger. eDucAçÃo MAteMátiCA AefeTIvA: nomes e movimentos em avessos. Bolema, Rio Claro (SP), v. 29, n. 53, p. 794-808, dez. 2015. Disponível em: http://www.scielo.br/scielo.php?script=sci_arttext\&pid=S0103-636X2 015000300794\&lng=en\&nrm=iso. Acesso em: 01 out. 2018.

CORAZZA, Sandra Mara (org.). Docência-pesquisa da diferença: poética de arquivomar. Porto Alegre: Doisa; UFRGS, 2017.

CORAZZA, Sandra Mara. O que faz gaguejar a linguagem da escola. In: ENDIPE (Encontro Nacional de Didática e Prática de Ensino). Linguagens, espaços e tempos no ensino e aprender. Rio de Janeiro: DP\&A, 2000. p. 89-103. 
DELEUZE, Gilles. Diferença e repetição. Rio de Janeiro: Graal, 2006.

DELEUZE, Gilles. Lógica do sentido. São Paulo: Editora Perspectiva, 2000.

DELEUZE, Gilles. Nietzsche e a filosofia. Porto: Rés-editora, 2001.

DELEUZE, Gilles. Crítica e clínica. São Paulo: Editora 34, 1997.

DELEUZE, Gilles; GUATTARI, Félix. Kafka: para uma literatura menor. Belo Horizonte: Autêntica, 2014.

DELEUZE, Gilles; GUATTARI, Félix. Mil platôs 1: capitalismo e esquizofrenia. São Paulo: Editora 34, 1995a.

DELEUZE, Gilles; GUATTARI, Félix. Mil platôs 2: capitalismo e esquizofrenia. São Paulo: Editora 34, 1995b.

DELEUZE, Gilles; GUATTARI, Félix. Mil platôs 4: capitalismo e esquizofrenia. São Paulo: Editora 34, 1997.

DELEUZE, Gilles; GUATTARI, Félix. O que é a filosofia? São Paulo: Editora 34, 1992.

DELEUZE, Gilles; PARNET, Claire. Diálogos. São Paulo: Editora Escuta,1998.

DIAS, Rosimeri de O. Deslocamentos na formação de professores: aprendizagens de adultos, experiências e políticas cognitivas. Rio de Janeiro: Lamparina, 2011.

FERRAÇO, Carlos E. Currículos em redes. Curitiba/PR: CRV, 2016.

FOUCAULT, Michel. Em defesa da sociedade. São Paulo: Martins Fontes, 1999.

FOUCAULT, Michel. Segurança, território, população. São Paulo: Martins Fontes, 2008.

GALLO, Silvio. Metodologia do ensino de filosofia: Uma didática para o ensino médio. Campinas: Papirus editora, 2012.

GELAMO, Rodrigo P. O ensino da filosofia no limiar da contemporaneidade: o que faz o filósofo quando seu ofício é ser professor de filosofia? São Paulo: Cultura Acadêmica, 2009.

MOLIN, Fábio D. Rizomas e fluxos molares e moleculares da máquina-escola: confissões de um cartógrafo. Psicologia e sociedade, Florianópolis, v. 23, n. 2, p. 303-311, ago. 2011. Disponível em: http://www.scielo.br/scielo.php?script=sci_arttext\&pid=S010271822011000200011\&lng=pt\&nrm=iso. Acesso em: 01 out. 2018.

MEYER, Dagmar E.; PARAÍSO, Marlucy Alves (orgs.) Metodologias de Pesquisas Pós-críticas em Educação. 2. ed. Belo Horizonte: Mazza Edições, 2012.

NIETZSCHE, Friedrich. A gaia ciência. São Paulo: Companhia das Letras, 2001.

NIETZSCHE, Friedrich. Genealogia da moral: uma polêmica. São Paulo: Companhia das Letras, 1998. 
OLIVEIRA, Andréia M.; FONSECA, Tania M. G. Os devires do território-escola: trajetos, agenciamentos e suas múltiplas paisagens. Educação \& Realidade, Porto Alegre, v. 31, n. 2, jul.-dez. 2006. p. 135-154. Disponível em: https://seer.ufrgs.br/educacaoerealidade/ article/view/6849. Acesso em: 01 out. 2018.

PASSOS, Eduardo; KASTRUP, Virgínia; ESCÓSSIA, Liliana. Pistas do método da cartografia: pesquisa intervenção e produção de subjetividade - v. 1. Porto Alegre: Sulina, 2014.

PASSOS, Eduardo; KASTRUP, Virgínia; Tedesco, Silvia. Pistas do Método da Cartografia: A experiência da pesquisa e o plano comum - v. 2. Porto Alegre: Sulina, 2016.

RODRIGUES, Carla G.; SCHWANTZ, Josimara W. Buracos negros na formação inicial de professores de matemática. Bolema, Rio Claro, v. 30, n. 56, p. 939-953, dez. 2016. Disponível em: http:/www.scielo.br/scielo.php?script=sci_arttext\&pid=S0103-636X2 016000300939\&lng=en\&nrm=isso. Acesso em: 01 out. 2018.

Texto recebido em 11/11/2019.

Texto aprovado em 24/02/2020. 